\title{
Tiotropium Respimat increases the risk of mortality: pro
}

\author{
Richard Beasley
}

Affiliation: Medical Research Institute of New Zealand, Wellington, New Zealand.

Correspondence: R. Beasley, Medical Research Institute of New Zealand, Private Bag 7902, Wellington 6242 , New Zealand. E-mail: Richard.Beasleyamrinz.ac.nz

0 @ERSpublications

Tiotropium Respimat increases mortality risk. First do no harm. Tiotropium Respimat should not be prescribed in COPD http://ow.ly/mzPGL

Systematic reviews and meta-analyses of randomised controlled trials of medications provide a high standard of evidence to inform clinical practice, and can be considered the "gold standard" for assessing the risk/benefit profile of treatments $[1,2]$. Three systematic reviews and meta-analyses (including a Cochrane Review) of randomised placebo-controlled trials of tiotropium Respimat, each using different methods, have demonstrated a $50 \%$ increased risk of mortality, with its use in patients with chronic obstructive pulmonary disease (COPD) [3-5]. These analyses provide substantive evidence that tiotropium Respimat increases mortality in the treatment of COPD [6,7]. It is informative to review each of the systematic reviews and the issues that have been raised relevant to their interpretation.

In 2011 the British Medical Journal (BMJ) published the first systematic review and meta-analysis, which included all parallel-group, randomised, placebo-controlled trials of tiotropium Respimat in the treatment of COPD that had reported data on mortality and were of a minimum 30-day duration [3] (table 1 [8-10]). Five trials were included in the analysis, two 12-week trials and three 12-month trials, studying 6522 participants. All five trials were judged to be at low risk of bias. Tiotropium Respimat significantly increased the risk of all-cause mortality, relative risk 1.52 (95\% CI 1.06-2.16). There was an apparent dose-response effect on all-cause mortality, with RR 1.46 (95\% CI 1.01-2.10) and 2.15 (95\% CI 1.03-4.51), for the 5- $\mu \mathrm{g}$ and $10-\mu$ g preparations, respectively (fig. 1 ). The overall estimates were not substantially changed by sensitivity analyses using the random effects model, limiting the analysis to three trials of 1-year duration period each, or the inclusion of additional preliminary data on tiotropium Respimat from an unpublished study. An accompanying editorial calculated, based on these figures, that one excess death is expected for every 121 (COPD) patients treated with a $5 \mu \mathrm{g}$ dose of tiotropium by Respimat for 12 months [11].

The 2012 Cochrane Review of tiotropium included the same five randomised placebo-controlled clinical trials of tiotropium Respimat, but used the Peto method for pooled estimation of odds ratio, which is arguably more appropriate for the combined analysis of rare events such as death [4]. Tiotropium Respimat significantly increased the risk of mortality, OR 1.47 (95\% CI 1.04-2.08). In contrast there was no increased risk of mortality with tiotropium HandiHaler, OR 0.92 (95\% CI 0.80-1.05).

In 2012 Thorax published a systematic review with direct comparison and mixed treatment comparison meta-analyses of randomised controlled trials of medications used in the treatment of COPD that provided data about overall or cardiovascular death, and were a minimum 6 months in trial duration [5]. In the direct comparison meta-analysis, tiotropium Respimat increased the risk of death compared with placebo, OR 1.49 (95\% CI 1.05-2.11). The risk was higher for cardiovascular death, in patients with severe COPD and at a higher daily dose. Tiotropium Respimat also increased the risk of death compared with other commonly used inhaled medications for COPD, including tiotropium HandiHaler, OR 1.65 (95\% CI 1.13-2.43), long-acting

Received: March 72013 | Accepted after revision: April 142013

Conflict of interest: Disclosures can be found alongside the online version of this article at www.erj.ersjournals.com

Copyright @ERS 2013 
TABLE 1 Key characteristics and findings of the published randomised placebo-controlled trials of tiotropium Respimat included in analysis of mortality

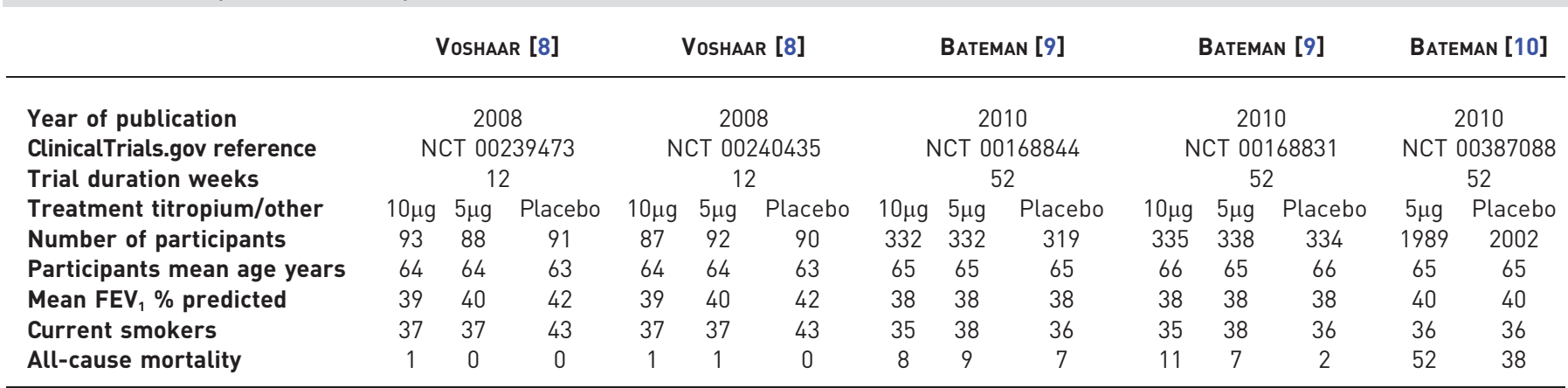

Data presented as $\mathrm{n}$ unless otherwise stated. $\mathrm{FEV}_{1}$ : forced expiratory volume in $1 \mathrm{~s}$.

$\beta$-agonists, OR 1.63 (95\% CI 1.10-2.44), and long-acting $\beta$-agonist/inhaled corticosteroid combination therapy, OR 1.90 (95\% CI 1.28-2.86).

There have been 10 important issues raised in relation to the interpretation of these systematic reviews and meta-analyses, and the individual studies on which they are based.

\section{Validity of analyses}

It has been proposed by Boehringer Ingelheim, the sponsor of the tiotropium clinical trials programme and manufacturer of the tiotropium Respimat and HandiHaler products, that alternative estimates of mortality risk, which are not statistically significant, can be derived by undertaking multiple "sensitivity analyses" based on different mortality datasets $[12,13]$. However, the consistent finding of a statistically significant increased risk of mortality with tiotropium Respimat obtained by the three, independent, meta-analyses is more likely to be valid.

\section{Analysis of mortality}

It has been proposed that analysing mortality is unjustified as it was not the primary endpoint in the clinical trials and, as such, should be viewed as hypothesis-generating [14]. However, this viewpoint is flawed [15]. Death caused by treatment is clearly a key secondary outcome relevant to both patients and clinicians, and there was a strong a priori reason for examining mortality due to the initial clinical trial programmes that suggested that both ipratropium bromide and tiotropium may increase the risk of mortality [16]. The reporting of mortality is mandatory [17], mortality can be reliably and objectively verified and there is no methodological reason to dismiss the findings. A weak argument can be made that choosing different endpoints in secondary analyses may inflate Type I error rates in a relatively limited dataset. However, this issue applies to multiple sensitivity analyses of mortality based on different datasets [12, 13], rather than the primary analysis of mortality as undertaken in the independent meta-analyses. As death is an important adverse outcome and COPD is a common disease, consideration of the mortality findings is crucial in determining the risk/benefit profile of this medication.

\section{All-cause mortality and cause-specific mortality}

The critique that the causes of death were diverse [12] is weak, as that is simply the nature of all-cause mortality. Previous research has shown that allocation of the cause of death in clinical trials of tiotropium is not straightforward and that "all-cause" mortality may be a stronger endpoint than cause-specific mortality because of diagnostic uncertainty [18]. Despite this, both the BMJ and Thorax systematic reviews found an increased risk of cardiovascular death with tiotropium Respimat compared with placebo, RR 2.05 (95\% CI 1.06-3.99) [3], and OR 1.96 (95\% CI 1.07-3.60) [5], respectively. This twofold increase in cardiovascular mortality accounts for about half the increase in all-cause mortality.

\section{Imbalance in randomisation}

The critique that the increase in mortality with tiotropium Respimat could be attributed to an unusually low rate of mortality in the placebo group of these trials [19], challenges the validity of well-designed and conducted, randomised, placebo-controlled trials. A systematic failure of randomisation in all five clinical trials, which provide the evidence base, is highly unlikely. Both the tiotropium Respimat and the placebo 


\begin{tabular}{|c|c|c|c|c|c|c|}
\hline \multirow{2}{*}{ Tiotropium $5 \mu \mathrm{g}$} & \multicolumn{2}{|c|}{ Events/participants $\mathrm{n}$} & \multirow{2}{*}{\multicolumn{2}{|c|}{$\begin{array}{c}\text { Risk ratio } \\
\text { Mantel-Haenszel } \\
\text { fixed }(95 \% \mathrm{Cl})\end{array}$}} & \multirow{3}{*}{$\begin{array}{c}\text { Weight } \\
\%\end{array}$} & \multirow{3}{*}{$\begin{array}{c}\text { Risk ratio } \\
\text { Mantel-Haenszel } \\
\text { fixed }(95 \% \mathrm{CI}) \\
\text { Not estimable }\end{array}$} \\
\hline & \multirow{2}{*}{$\begin{array}{c}\text { Tiotropium } \\
\text { mist inhaler } \\
0 / 88\end{array}$} & \multirow{2}{*}{$\begin{array}{c}\text { Placebo } \\
\text { 0/91 }\end{array}$} & & & & \\
\hline VoshaAr [8] & & & & & & \\
\hline VoshaAR [8] & $1 / 92$ & $0 / 90$ & & & 1.1 & $2.94(0.12-1.12)$ \\
\hline BATEMAN [9] & $9 / 332$ & $7 / 319$ & & $=$ & 15.0 & $1.24(0.47-3.28)$ \\
\hline BATEMAN [9] & $7 / 338$ & $2 / 334$ & & & 4.2 & $3.46(0.72-16.53)$ \\
\hline Bateman [10] & $52 / 1989$ & $38 / 2002$ & & $\square$ & 79.7 & $1.38(0.91-2.08)$ \\
\hline Total $(95 \% \mathrm{Cl})$ & $69 / 2839$ & $47 / 2836$ & & $<$ & 100.0 & $1.46(1.01-2.10)$ \\
\hline \multicolumn{3}{|c|}{ Test for heterogeneity: $\chi^{2}=1.54, d f=3, p=0.67,1^{2}=0 \%$} & & & & \\
\hline \multicolumn{3}{|c|}{ Test for overall effect: $z=2.03, p=0.04$} & & & & \\
\hline \multicolumn{3}{|l|}{ Tiotropium $10 \mu \mathrm{g}$} & & & & \\
\hline VoshaAR [8] & $1 / 93$ & $0 / 91$ & & $=$ & 5.0 & $2.94(0.12-71.15)$ \\
\hline VoshaAr [8] & $1 / 87$ & $0 / 90$ & & & 4.8 & $3.10(0.13-75.14)$ \\
\hline BATEMAN [9] & $8 / 332$ & $7 / 319$ & & 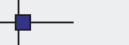 & 70.4 & $1.10(0.40-2.99)$ \\
\hline BATEMAN [9] & $11 / 335$ & $2 / 334$ & & & 19.8 & $5.48(1.22-24.55)$ \\
\hline Total $(95 \% \mathrm{CI})$ & $21 / 847$ & $9 / 834$ & & $<$ & 100.0 & $2.15(1.03-4.51)$ \\
\hline \multicolumn{3}{|c|}{ Test for heterogeneity: $\chi^{2}=3.31, d f=3, p=0.35,1^{2}=9 \%$} & & & & \\
\hline \multirow{2}{*}{\multicolumn{3}{|c|}{ Test for overall effect: $z=2.03, p=0.04$}} & $0.05 \quad 0.2$ & 1 & 20 & \\
\hline & & & $\begin{array}{l}\text { Less harm } \\
\text { with mist } \\
\text { inhaler }\end{array}$ & $\begin{array}{l}\text { Less h } \\
\text { with pl }\end{array}$ & & \\
\hline
\end{tabular}

FIGURE 1 Meta-analysis of the risk of all-cause mortality with tiotropium delivered by the Respimat Soft Mist Inhaler $(5 \mu \mathrm{g}$ or $10 \mu \mathrm{g}$ ) from published, randomised, placebo-controlled trials of patients with chronic obstructive pulmonary disease. Reproduced and modified from [3] with permission from the publisher.

groups had comparable baseline characteristics in all the trials (table 1) and there was adequate allocation concealment during randomisation $[3,4]$.

\section{Higher withdrawal rate with placebo}

This potential bias was minimised by the steps taken by the trial investigators to ascertain the vital status of all randomised patients, even if they had discontinued treatment, thereby achieving almost complete capture of the mortality outcomes [3]. For example, in the largest 1-year study the vital status was known for $\geqslant 99 \%$ of randomised patients for the primary analysis of death by the end of the planned treatment period (day 337) [10]; in the combined analysis of the other two 1-year studies, vital status was known for $97.7 \%$ of randomised patients for the primary analysis of death by the end of the planned treatment and 30day follow-up observation period (day 366) $[9,20]$.

\section{Inclusion of $10 \mu \mathrm{g}$ data}

The suggestion that $10 \mu \mathrm{g}$ data should not be included in the meta-analyses because tiotropium Respimat is not marketed in this dose [12] contradicts the Cochrane Handbook that recommends an amalgamation of all treatment arms into one group [21]. Importantly it provides evidence of a probable dose-response relationship of tiotropium Respimat and mortality, which further supports a causal relationship. Inclusion of data from the higher dose arms of the studies is also relevant to patients with renal impairment, as tiotropium is renally excreted and plasma concentrations are around twofold higher in moderate-to-severe renal impairment [22]. Despite this, the two meta-analyses, which reported data on the $5 \mu \mathrm{g}$ preparation alone, both reported an increased risk of death of 1.46 (95\% CI 1.01-2.10) [3] (fig. 1) and 1.46 (95\% CI 1.01-2.14) [5], respectively, and a $5 \mu \mathrm{g}$ dose was also associated with an increased risk of cardiovascular death, OR 2.18 (95\% CI 1.15-4.41) [5].

\section{Underestimate of risk}

The estimates of risk from the tiotropium Respimat research programme are likely to underestimate the actual risk of mortality in an unselected group of COPD patients with cardiovascular comorbidity. In this 
regard, the exclusion criteria in the largest tiotropium Respimat study included a recent history of unstable arrhythmias, myocardial infarction or heart failure requiring hospital admission [10], thereby specifically ensuring the exclusion of patients at highest risk of cardiovascular mortality. The importance of cardiovascular comorbidity in determining this risk is illustrated in the Food and Drug Administration (FDA) review of this study, in which even after exclusion of such high-risk patients, those with a baseline history of cardiac disease or cardiac rhythm disorder had a markedly increased risk of cardiac death with $5 \mu \mathrm{g}$ of tiotropium Respimat, RR 4.03 (95\% CI 1.15-14.13) and 8.61 (95\% CI 1.10-67.23), respectively [20].

\section{Differential risk with tiotropium products}

Both the Cochrane [4] and Thorax [5] meta-analyses have reported no effect of tiotropium HandiHaler on mortality risk, and a significant difference in mortality risk between the HandiHaler and Respimat inhalers. It has been suggested that this difference may weaken the evidence of mortality risk with tiotropium Respimat [12]. There are at least three possible explanations that may account for the differential risk of the two formulations of tiotropium. Firstly, inhalation of the $5 \mu \mathrm{g}$ and $10 \mu \mathrm{g}$ doses of tiotropium from the Respimat device may result in greater systemic exposure to tiotropium than the $18 \mu \mathrm{g}$ dose from the Handihaler device. In pharmacokinetic studies, two to threefold higher peak and steady-state plasma concentrations have been demonstrated with the $10 \mu \mathrm{g}$ dose by Respimat compared with the $18 \mu \mathrm{g}$ tiotropium dose from the HandiHaler, whereas the 6-35\% higher concentrations with the $5 \mu$ g dose via Respimat are less marked $[23,24]$.

The second possibility is that the tiotropium Respimat studies may have been more likely to have included patients at increased risk with tiotropium, in particular those with known cardiac rhythm disorders [7]. This issue has proven difficult to assess, due to the marked inconsistencies in the reporting of exclusion criteria between the sponsor's unpublished study protocols, the publically registered protocols and the published manuscripts for the tiotropium Respimat studies. Furthermore, COPD populations screened for inclusion in the studies are likely to vary between centres, and overarching exclusion criteria such as "patients who had a disease that might put them at risk because of study participation" are sensitive to investigator interpretation, resulting in selection biases that may be very difficult to ascertain post hoc, making it difficult to determine which patients were excluded [7]. However, in support of this possibility, data submitted to the FDA [25] indicates that patients with a history of cardiac rhythm disorders were more likely to be enrolled in the major tiotropium Respimat study [10], than in the major tiotropium Handihaler study [26], (11.8\% versus $6.8 \%$, respectively, RR $1.72(1.54-1.96))$.

The third possibility is that repeated exposure to low concentrations of the antibacterial agent benzalkonium chloride included together with the stabilising agent ethylene diamine tetra-acetic acid (EDTA) in the tiotropium Respimat, but not HandiHaler device, may lead to adverse effects [27]. Benzalkonium chloride has bronchoconstrictor properties, being only 7.4 times less potent as a bronchoconstrictor agonist than histamine [28-30]. Furthermore, exposure to benzalkonium chloride is a recognised cause of occupational asthma [31-33]. The administration of placebo Respimat solution containing benzalkonium chloride in a concentration of $100 \mu \mathrm{g} \cdot \mathrm{mL}^{-1}$ causes bronchoconstriction with a fall in forced expiratory volume in $1 \mathrm{~s}$ (FEV1 ) of $\geqslant 15 \%$ from baseline in $4.3 \%$ of occasions in patients with COPD [34]. While this bronchoconstriction is prevented with the inclusion of tiotropium in the Respimat solution containing benzalkonium chloride it shows the potential acute airways effects of benzalkonium chloride in COPD [34]. The long-term airways effects of repeated administration of benzalkonium chloride and EDTA in COPD have not been studied.

\section{Biological plausibility}

There is biological plausibility in that inhaled anticholinergic medications have pro-arrhythmic effects, which have been associated with increased risk of cardiac mortality [35]. Their importance is also suggested by the observation that the increased mortality risk with tiotropium Respimat is present in patients with a history of a cardiac rhythm disorder rather than coronary artery disease [20]. Biological plausibility is also suggested by the observation that ipratropium bromide increases cardiovascular risk, thereby suggesting that the increase in risk may represent a class effect of inhaled anticholinergic agents. This was originally observed in the Lung Health Survey, in which the regular use of ipratropium bromide by metered dose inhaler increased the risk of cardiovascular death, RR 2.57 (95\% CI 1.12- 6.62) [36]. Ipratropium bromide was also noted to increase the risk of hospital admission due to arrhythmias with a relatively high prevalence of supraventricular tachycardia. Subsequently, a systematic review and meta-analysis of five trials, including 6,155 subjects, reported that ipratropium bromide increased the risk of the primary composite endpoint of cardiovascular death, myocardial infarction or stroke, RR 1.70 (95\% CI 1.19-2.42) [16]. 


\section{Generalisability}

The generalisability of the findings to clinical practice is shown by a recent study from a Dutch general practice database [37]. The use of tiotropium Respimat was associated with an increased risk of dying, hazard ratio 1.27 (95\% CI 1.03-1.57) with the highest risk for cardiovascular/cerebrovascular death, HR 1.56 (95\% CI 1.08-2.25). The risk was present in patients with coexisting cardiovascular disease, HR 1.36 (95\% CI 1.07-1.73) rather than in patients without, HR 1.02 (95\% CI 0.61-1.71). This extension of the mortality findings from randomised placebo-controlled trials to a real world non-experimental study provides evidence of a consistent effect with different study designs.

\section{Conclusions}

In conclusion, the three systematic reviews and meta-analyses of randomised placebo-controlled trials, undertaken by independent groups of investigators using different methods, provide level $1+$ scientific evidence (well conducted meta-analyses of randomised placebo-controlled trials with a low risk of bias) that tiotropium Respimat increases the risk of cardiovascular and all-cause death. To propose otherwise challenges internationally accepted principles of evidence-based medicine. In the absence of evidence of greater clinical benefit with tiotropium Respimat compared with tiotropium HandiHaler [38], a recommendation can be made that the $5 \mu \mathrm{g}$ and $10 \mu \mathrm{g}$ preparations of tiotropium Respimat should not be prescribed in the treatment of COPD $[6,7]$.

\section{References}

Harbour R, Miller J. A new system for grading recommendations in evidence based guidelines. BMJ 2001; 323: 334-336. Sackett D, Rosenberg WM, Gray JAM, et al. Evidence based medicine: what it is and what it isn't. BMJ 1996; 312: 71-72.

3 Singh S, Loke YK, Enright PL, et al. Mortality associated with tiotropium mist inhaler in patients with chronic obstructive pulmonary disease: systematic review and meta-analysis of randomized controlled trials. BMJ 2011; 342: d3215.

4 Karner C, Chong J, Poole P. Tiotropium versus placebo for chronic obstructive pulmonary disease. Cochrane Database Syst Rev 2012; 7: CD009285.

5 Dong YH, Lin HH, Shau WY, et al. Comparative safety of inhaled medications in patients with chronic obstructive pulmonary disease: systematic review and mixed treatment comparison meta-analysis of randomized controlled trials. Thorax 2013; 68: 48-56.

6 Beasley R, Singh S, Loke YK, et al. Call for worldwide withdrawal of tiotropium Respimat mist inhaler. BMJ 2012; 345: e7390.

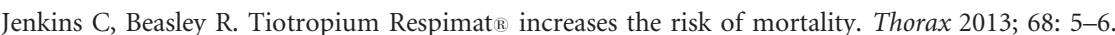

Voshaar T, Lapidus R, Maleki-Yazdi R, et al. A randomized study of tiotropium Respimat Soft Mist inhaler $v s$. ipratropium pMDI in COPD. Respir Med 2008; 102: 32-41.

9 Bateman E, Singh D, Smith D, et al. Efficacy and safety of tiotropium Respimat SMI in COPD in two 1-year randomized studies. Int J Chron Obstruct Pulmon Dis 2010; 5: 197-208.

10 Bateman ED, Tashkin D, Siafakas N, et al. A one-year trial of tiotropium Respimat plus usual therapy in COPD patients. Respir Med 2010; 104: 1460-1472.

Cates CJ. Safety of tiotropium. BMJ 2011; 342: d2970.

12 Disse B, Metzdorf N, Martin A, et al. Rapid response: Mortality associated with tiotropium mist inhaler? A critical appraisal of the authors' selection and use of previously communicated tiotropium Respimat data BMJ 2011; 342: d3215/r.

13 Singh S, Loke YL, Enright P, et al. Rapid response: Mortality associated with tiotropium mist inhaler? A critical appraisal of the authors' selection and use of previously communicated tiotropium Respimat data. BMJ 2011; 342: d3215/r.

14 Morice AH. Rapid response to: Call for worldwide withdrawal of tiotropium Respimat mist inhaler. BMJ 2012; 345 : e7390//rr/615667.

15 Beasley R, Singh. Loke YK, et al. Rapid response: Call for worldwide withdrawal of tiotropium Respimat mist inhaler. BMJ 2012; 345: e7390//rr/616980.

16 Singh S, Loke YN, Furberg CD. Inhaled anticholinergics and risk of major adverse cardiovascular events in patients with chronic obstructive pulmonary disease: a systematic review and meta-analysis. JAMA 2008; 300: 1439-1450.

17 ICH Expert Working Group. 4.11 safety reporting. In ICH Harmonised Tripartite Guideline. Guideline for Good Clinical Practice E6(R1). Available from: www.ich.org/products/guidelines/efficacy/article/efficacy-guidelines.html Date last accessed: January 2013.

18 McGarvey LP, Magder S, Burkhart D, et al. Cause-specific mortality adjudication in the UPLIFT COPD trial: findings and recommendations. Respir Med 2012; 106: 515-521.

19 Public Assessment Report of the Medicines Evaluation Board in the Netherlands. Spiriva Respimat 2.5 microgram, solution for inhalation: Boehringer Ingelheim International $\mathrm{GmbH}$, Germany tiotropium bromide monohydrate. MEB pursuant Article 21 (3) and (4) of Directive 2001/83/EC2008. Available from: http://db.cbg-meb.nl/mri/par/ nlh-0718-001.pdf Date last accessed: 4, 2013.

20 Pulmonary-Allergy Drugs Advisory Committee Meeting, US Food and Drug Administration. Clinical Briefing Document, November 19 2009. Overview of the FDA background materials for an efficacy supplement for NDA\# 21-395, for the approved product Spiriva HandiHaler (tiotropium bromide inhalation powder), for the reduction in exacerbations in patients with chronic obstructive pulmonary disease (COPD). Available from: www.fda.gov/downloads/ advisorycommittees/committeesmeetingmaterials/drugs/pulmonary-allergydrugsadvisorycommittee/ucm 190463.pdf Date last accessed: Aug 2012. 
21 Higgins JPT, Green S. Cochrane Handbook for Systematic Reviews of Interventions. Version 5.1.0. www.cochranehandbook.org/ Date last updated: March 2011. Date last accessed: July 4, 2013.

22 MedSafe, Ministry of Health New Zealand. Datasheet: Spiriva Totropium 18 mcg. Available from www.medsafe. govt.nz/profs/Datasheet/s/Spirivacap.pdf Date last accessed: Aug 2012. Date last updated: July 15, 2011.

23 van Noord JA, Cornelissen PJ, Aumann JL, et al. The efficacy of tiotropium administered via Respimat soft mist inhaler or HandiHaler in COPD patients. Respir Med 2009; 103: 22-29.

24 Ichinose M, Fujimoto T, Fukuchi Y. Tiotropium $5 \mu \mathrm{g}$ via Respimat and $18 \mu \mathrm{g}$ via HandiHaler; efficacy and safety in Japanese COPD patients. Respir Med 2010; 104: 228-236.

25 Boehringer Ingelheim. Briefing Document: Tiotropium (SPIRIVA): Pulmonary Allergy Drug Advisory Meeting November 2009. Available from: www.fda.gov/downloads/AdvisoryCommittees/CommitteesMeetingMaterials/ Drugs/Pulmonary-AllergyDrugsAdvisoryCommittee/UCM190466.pdf Date last accessed: Jan 2013. Date last updated: October 15, 2009.

26 Tashkin DP, Celli B, Senn S, et al. A 4-year trial of tiotropium in chronic obstructive pulmonary disease. $N$ Engl J Med. 2008; 359: 1543-1554.

27 Seed MJ, Agius R. Rapid response: Another plausible explanation for mist inhaler's toxicity. BMJ 2011; 342: d3215/rr

28 Rafferty P, Beasley R, Holgate ST. Comparison of the efficacy of preservative free ipratropium bromide and Atrovent nebuliser solution. Thorax 1988; 43: 446-450.

29 Zhang YG, Wright WJ, Tam WK, et al. Effect of inhaled preservatives on asthmatic subjects. II Benzalkonium chloride. Am Rev Respir Dis 1990; 141: 1405-1408.

30 Miszkiel KA, Beasley R, Rafferty P, et al. The contribution of histamine release to bronchoconstriction provoked by inhaled benzalkonium chloride in asthma. Br J clin Pharmac 1988; 25: 157-163.

31 Innocenti A. Asma professionale da benzalconio cloruro [Occupational asthma due to benzalkonium chloride]. Med Lav 1978; 69: 713-715.

32 Burge PS, Richardson MN. Occupational asthma due to indirect exposure to lauryl dimethyl benzyl ammonium chloride used in a floor cleaner. Thorax 1994; 49: 842-843.

33 Purohit A, Kopferschmitt-Kubler MC, Moreau C, et al. Quaternary ammonium compounds and occupational asthma. Int Arch Occup Environ Health 2000; 73: 423-427.

34 Koehler D, Pavia D, Dewberry H, et al. Low incidence of paradoxical bronchoconstriction with bronchodilator drugs administered by Respimat soft mist inhaler: results of phase II single-dose crossover studies. Respiration 2004; 71: 469-476.

35 Singh S, Loke YK, Enright P, et al. Pro-arrhythmic and pro-ischaemic effects of inhaled anticholinergic medications. Thorax 2012; 68: 114-116.

36 Anthonisen NR, Connett JE, Enright PL, et al. Hospitalizations and mortality in the Lung Health Study. Am J Respir Crit Care Med 2002; 166: 333-339.

37 Verhamme KMC, Afonso A, Romio S, et al. Use of tiotropium Respimat Soft Mist Inhaler versus Handihaler and mortality in patients with COPD. Eur Respir 2013; 42: 606-615.

38 Ram FS, Carvallho CR, White J. Clinical effectiveness of the Respimat inhaler device in managing chronic obstructive pulmonary disease: evidence when compared with other handheld inhaler devices. Int J Chron Obstruct Pilmon Dis 2011; 6: 129-139. 